\title{
A Prospective Study with Cage-Only or Cage-with-Plate Fixation in Anterior Cervical Discectomy and Interbody Fusion of One and Two Levels
}

\author{
Sam Yeol Kim, M.D., ${ }^{1}$ Seung Hwan Yoon, M.D., Ph.D., ${ }^{1}$ Dokeun Kim, M.D., ${ }^{1}$ Chang Hyun Oh, M.D., ${ }^{2}$ Seyang Oh, M.D. \\ Department of Neurosurgery, Inha University School of Medicine, Incheon, Korea \\ Guri Cham Teun Teun Hospital, ${ }^{2}$ Guri, Korea
}

Objective : The authors prospectively analyzed the effect of one-level or two-level anterior cervical discectomy and fusion (ACDF), comparing stand-alone cages and cage-with-plate fixation constructs with respect to clinical outcomes and radiologic changes.

Methods : A total of 84 patients who underwent one-level $(n=52)$ or two-level ACDF $(n=32)$ for cervical disc disease and who completed 2 years of follow-up were included in this study. The patients were divided by cervical level and grouped into ACDFCage-only and ACDF-Cage-with-plate groups. The following parameters were assessed using radiographs : subsidence, C2-C7 lordosis angle, fusion segment angle, adjacent disc space narrowing, and fusion status. Clinical outcomes were assessed using the neck disability index (NDI) and visual analog scale scores for arm pain.

Results : In the comparison of one-level ACDF-cage-only and ACDF-cage-with-plate groups, the NDI score was better in the cageonly group at the 3-, 12-, and 24-month follow-ups : however, no significant difference in clinical outcomes was observed. In the comparison of two-level ACDF-cage-only and ACDF-cage-with-plate groups, no difference in any clinical outcome was observed between the two groups. At the 24-month follow-up, subsidence was observed in $45.8 \%$ of patients in the one-level cage-only group and $32.1 \%$ of patients in the one-level cage-with-plate fixation group. There was no statistically significant difference in the incidence rate between the two groups ( $p=0.312$ ). Subsidence in the two-level cage-only group (66.6\%) was significantly more frequent than in the two-level cage-with-plate fixation group $(30 \% ; p=0.049)$. The fusion rate for patients in the one-level cage-only group was not significantly different from that in the one-level cage-with-plate fixation group (cage-only, 87.5\%; cage-with-plate fixation, $92.9 \% ; p=0.425$ ) ; fusion rate in the two-level patients were also similar between groups (cage-only, 83.3\%; cage-with-plate fixation, $95 \% ; p=0.31$.

Conclusion : Our clinical results showed that for single-level cases, plate fixation had no additional benefit versus cage-only; for two-level ACDF cases, the fusion rate and clinical outcomes were similar, although the cage-with-plate fixation group had a lower incidence of cage subsidence than did the cage-only group. We conclude that physicians should be aware of this possible disadvantage associated with using cervical plates in one-level ACDF. However, in two-level ACDF, subsidence is more likely to occur without plate fixation, and thus the addition of plate fixation should be considered.

Key Words : Diskectomy · Cervical vertebrae · Spinal fusion · Bone plate.

- Received : July 10, 2017 •Revised : August 18, 2017 •Accepted : August 30, 2017

- Address for reprints : Seung Hwan Yoon, M.D., Ph.D.

Department of Neurosurgery, Inha University School of Medicine, 27 Inhang-ro, Jung-gu, Incheon 22332, Korea

Tel : +82-32-890-2619, Fax : +82-32-890-3967, E-mail : nsyoon@gmail.com

This is an Open Access article distributed under the terms of the Creative Commons Attribution Non-Commercial License (http://creativecommons.org/licenses/by-nc/4.0) which permits unrestricted non-commercial use, distribution, and reproduction in any medium, provided the original work is properly cited. 


\section{INTRODUCTION}

Anterior cervical discectomy and interbody fusion (ACDF) has become the standard procedure for treating degenerative cervical disc disease ${ }^{4)}$. Multiple techniques and modalities of fixation are used in ACDF, each with its merits and demerits $^{26)}$. For example, autografts are associated with significant donor-site morbidity.

Due to these issues, interbody fusion via cage-only or cagewith-plate fixation is the main fusion technique used during ACDF operations ${ }^{10)}$. The advantage of using the anterior cervical plate lies in its ability to reinforce the stability of the fusion construct, while cage-only fixation is advantageous because of its shorter operating time, minimal blood loss, and simplicity.

Numerous studies have compared the clinical and radiologic outcomes of the cage-only and cage-with-plate fixation techniques. In some studies, cage-with-plate fixation had higher fusion rates and lower subsidence rates than did cageonly fixation ${ }^{2,67,29)}$, whereas other studies reported no difference between the two procedures ${ }^{3)}$. In a recently reported meta-analysis study, there was no difference in clinical and radiological outcomes between the cage-with-plate fixation group and the cage-only group in one-level $\mathrm{ACDF}^{19)}$.

We designed this study to verify the clinical and radiological outcomes between the two groups in one-level ACDF, and to see if there were differences in clinical and radiological outcome in two-level ACDF.

\section{MATERIALS AND METHODS}

\section{Materials}

Patients diagnosed as having degenerative cervical disc disease accompanied with arm pain, who received one-level or consecutive two-level ACDF cage-only and cage-with-plate fixation operations at our hospital between 2012 and 2015 who underwent follow-up of longer than 24 months, were enrolled for this prospective observational study. The study patients were divided into 4 groups depending on whether the operation was one- or two-level and whether plate fixation was used.

Fifty-two patients received one-level ACDF surgery; 24 of those patients received cage-only and 28 received cage-withplate fixation. Thirty-two patients received two-level ACDF surgery; 12 of those patients received cage-only and 20 received cage-with-plate fixation.

Interbody fusion was performed using a PEEK cage $(\mathrm{C}$ mightmus cage; DAEWONG BIO, Seoul, Korea). A PEEK cage packed with demineralized bone matrix was inserted into the disc space. In cases with plate augmentation, an anterior cervical plate (Maxima ACP; U\&I Corporation, Seoul, Korea) was used.

The mean age was $52.5(52.5 \pm 10.3)$ years in the one-level cage-only group and $50.4(50.4 \pm 12.1)$ years in the one-level cage-with-plate fixation group. The mean age was 60.7 (60.7 \pm 8.6) years in the two-level cage-only group and $53.1(53.1 \pm 12.5)$ years in the two-level cage plate group.

The one-level cage-only group consisted of 15 male and 9 female subjects and the one-level cage-with-plate fixation group consisted of 16 male and 12 female subjects. The twolevel cage-only group comprised 10 male and 2 female subjects and the two-level cage-with-plate fixation group comprised 14 male and 6 female subjects.

For the surgical level, the C5/6 level accounted for 9 patients in the cage-only group and 12 patients in the cage-with-plate fixation group. In the two-level fusion groups, C5/6/7 fusion was the most numerous in the cage-only group with 8 patients, whereas C4/5/6 fusion was the most common in the cage-with-plate fixation group with 10 patients (Table 1).

The demographic data did not show statistically significant differences.

\section{Methods}

Clinical and radiologic follow-up were performed prior to the operation and post-operatively at $1,3,6,12$, and 24 months. Clinical outcomes were assessed using the visual analog scale (VAS) for arm pain and neck disability index (NDI). Radiologic parameters were assessed by measuring the presence of cage subsidence, fusion, fusion segment angle, global cervical lordosis, and adjacent disc mid-height (Fig. 1) using C-spine anterior-posterior, lateral (neutral, flexion, and extension) plain radiographs prior to the operation and during the post-operative follow-up.

Fusion was defined as $<2^{\circ}$ movement on the lateral flexion/ extension views, the presence of bridging trabecular bone between the endplates on antero-posterior/lateral views, and $<50 \%$ radiolucency on the perimeter surrounding the cage ${ }^{11)}$.

For cage subsidence, the distance between the midpoint of 
Cage-Only vs. Plate Fixation in ACDF I Kim SY, et al.

Table 1. Demographic data between one-level CO vs. CP and two-level CO vs. CP

\begin{tabular}{|c|c|c|c|c|c|c|}
\hline Group & One level CO & One level CP & $p$-value & Two level CO & Two level CP & $p$-value \\
\hline Age (years) & $52.5 \pm 10.3(36-73)$ & $50.4 \pm 12.1(29-75)$ & $0.515^{*}$ & $60.7 \pm 8.6(50-72)$ & $53.1 \pm 12.5(44-74)$ & $0.074^{*}$ \\
\hline Sex & & & $0.702^{*}$ & & & $0.394^{*}$ \\
\hline Male & 15 & 16 & & 10 & 14 & \\
\hline Female & 9 & 12 & & 2 & 6 & \\
\hline \multicolumn{7}{|l|}{ Surgical level } \\
\hline $\mathrm{C} 3 / 4$ & 4 & 2 & $0.533^{\dagger}$ & & & \\
\hline$C 4 / 5$ & 2 & 5 & & & & \\
\hline C5/6 & 9 & 12 & & & & \\
\hline C6/7 & 9 & 8 & & & & \\
\hline $\mathrm{C} 7 / \mathrm{T} 1$ & 0 & 1 & & & & \\
\hline $\mathrm{C} 3 / 4 / 5$ & & & & 2 & 4 & $0.102^{\dagger}$ \\
\hline$C 4 / 5 / 6$ & & & & 2 & 10 & \\
\hline C5/6/7 & & & & 8 & 6 & \\
\hline Preop NDI & $16.7 \pm 7.5$ & $19.4 \pm 6.5$ & $0.173^{*}$ & $18.5 \pm 9.1$ & $19.1 \pm 6.9$ & $0.834^{*}$ \\
\hline Preop VAS & $7.1 \pm 2.0$ & $7.9 \pm 1.9$ & $0.138^{*}$ & $7.7 \pm 2.1$ & $6.5 \pm 1.9$ & $0.133^{*}$ \\
\hline
\end{tabular}

Values are presented as mean \pm standard deviation (range) or number. ${ }^{*}$ The Student t-test. ${ }^{\dagger}$ The $\chi^{2}$ test. CO : cage-only, CP : cage-with-plate, NDI : neck disability index, VAS : visual analog scale
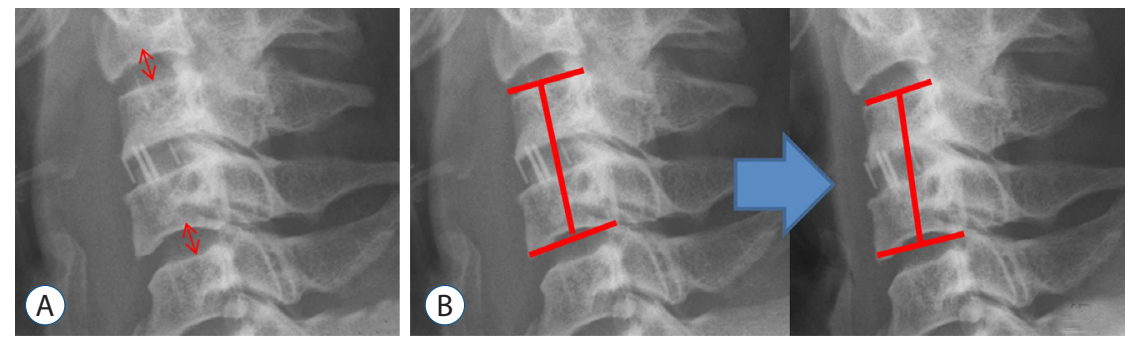

Fig. 1. A : The adjacent disc mid-height $(\mathrm{mm})$ was measured, and adjacent disc degeneration was compared. B : Subsidence was defined as the condition when the distance $(\mathrm{mm})$ between the midpoint of the upper vertebra of the fusion segment, and the midpoint of the inferior endplate of the lower vertebra showed a difference of more than $2 \mathrm{~mm}$ between the pre-operative and 24-month X-rays. C : Fusion segment angle : Cobb's angle $\left(^{\circ}\right)$ between the superior endplate of the upper vertebra of the fusion segment and the inferior endplate of the lower vertebra was measured from the lateral plain radiograph. $\mathrm{D}:$ To assess global cervical lordosis, Cobb's angle $\left(^{\circ}\right)$ between the posterior margin of the $\mathrm{C} 2$ and $\mathrm{C} 7$ vertebral bodies was measured.

the superior endplate of the upper vertebra of the fusion segment and the midpoint of the inferior endplate of the lower vertebra was measured in the lateral plain radiograph and compared using the pre-operative (pre-op) and 24-month follow-up images. In the case of one-level ACDF using $2 \mathrm{~mm}$ as the reference, the presence of subsidence was defined as the condition when the difference was larger than $2 \mathrm{~mm}$. In the case of two-level ACDF using $4 \mathrm{~mm}$ as the reference, the presence of subsidence was defined when the difference was larger than $4 \mathrm{~mm}$ (Fig. 1) $)^{21)}$. 
For the fusion segment angle, the Cobb's angle between the superior endplate of the upper vertebra of the fusion segment and the inferior endplate of the lower vertebra was measured in the lateral plain radiograph (Fig. 1).

For the global cervical lordosis, the Cobb's angle between the posterior margin of the vertebral bodies of $\mathrm{C} 2$ and $\mathrm{C} 7$ was measured (Fig. 1).

Student's t-tests, chi-squared tests and Fisher's exact tests were used to confirm the statistical significance of differences in radiologic and clinical outcomes between the two groups. All statistical analyses were performed using SPSS software (SPSS Inc., Chicago, IL, USA), and the statistical significance was defined as $p<0.05$.

This study was approved by the Institutional Review Board of Inha University Hospital (IRB No. 47621-01). Written informed consent was obtained from all patients.

VAS

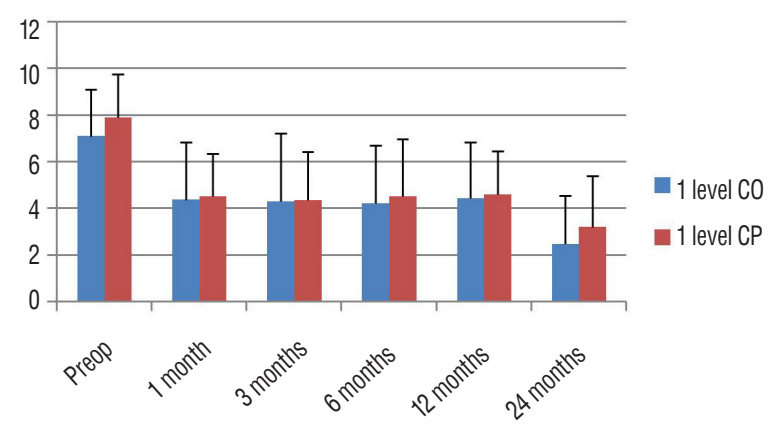

(A)

NDI (\%)

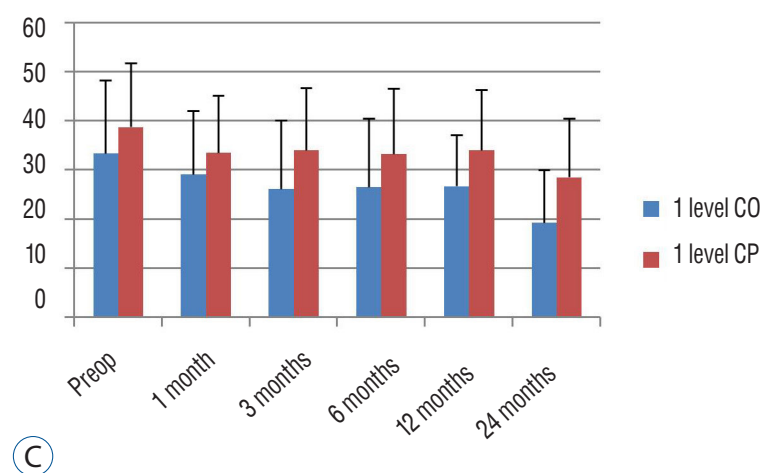

\section{RESULTS}

\section{Clinical results}

The mean pre-op VAS score was $7.08 \pm 2.02$ in the one-level cage-only group and $7.89 \pm 1.85$ in the cage-with-plate fixation group. The follow-up mean VAS at 24 months was 2.46 \pm 2.06 in the one-level cage-only group and $3.18 \pm 2.21$ in the cagewith-plate fixation group, both of which represent tangible improvement. There was no statistically significant difference during the follow-up periods (Fig. 2).

In the two-level fusion groups, the pre-op mean VAS score was $7.67 \pm 2.15$ in the cage-only group and $6.5 \pm 1.85$ in the cagewith-plate fixation group. The follow-up mean VAS at 12 months was $3.57 \pm 1.94$ in the two-level cage-only group and $5.12 \pm 1.34$ in the cage-with-plate fixation group. Although the VAS score was significantly lower in the cage-only group
VAS

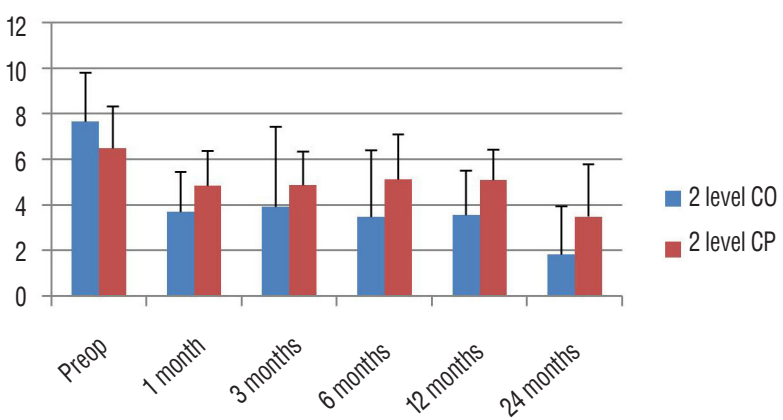

(B)

NDI (\%)

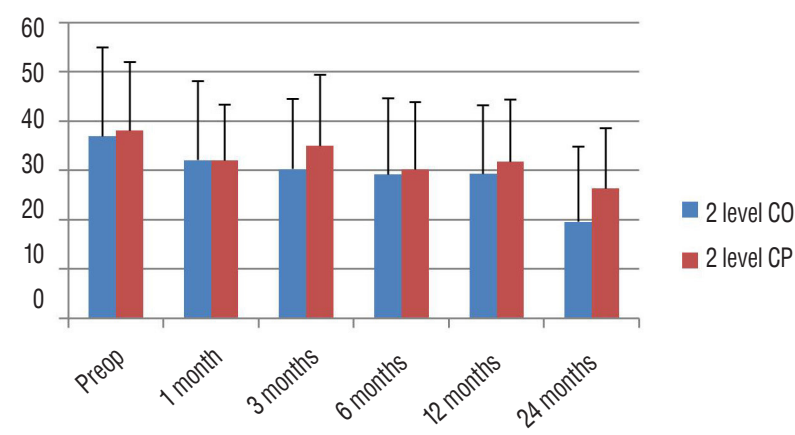

(D)

Fig. 2. A and B : Comparison of visual analog scale (VAS) score (Arm) between one-level cage-only (CO) vs. cage-with-plate (CP) (A) and two-level CO vs. $\mathrm{CP}$ fixation (B). C and D: Comparison of neck disability index (NDI) scores between one-level CO vs. CP (C) and two-level CO vs. CP fixation (D). 
( $p=0.026$ ), the follow-up mean VAS at 24 months was not significantly different (Fig. 2).

The pre-op mean NDI score was $33.42 \pm 14.93$ in the one-level cage-only group and $38.79 \pm 13.07$ in the one-level cage-withplate fixation group $(p=0.173)$. The mean NDI score was significantly lower in the cage-only group at 3-month follow-ups (26.16 \pm 13.93 and $34.05 \pm 12.75, p=0.039$ ), 12-month follow-ups (26.74 \pm 10.42 and $34.05 \pm 12.33, p=0.025)$, and 24 -month followups (19.33 \pm 10.72 and $28.57 \pm 12, p=0.005)$ (Fig. 2).

The pre-op mean NDI score was $37.0 \pm 18.12$ in the two-level cage-only group and $38.20 \pm 13.84$ in the cage-with-plate fixation group ( $p=0.846$ ), and no statistically significant difference was observed among any follow-up periods (Fig. 2).

\section{Radiologic results}

At the 24-month follow-up, subsidence was observed in 11 out of 24 patients in the one-level cage-only group (45.8\%) and 9 out of 28 patients in the one-level cage-with-plate fixation group (32.1\%). There was no statistically significant difference in the incidence rate between the two groups $(p=0.312)$ (Table 2).

At the 24-month follow-up, subsidence was observed in 8 out of 12 patients in the two-level cage-only group (66.6\%) and 6 out of 20 patients in the two-level cage-with-plate fixation group (30\%). The odds ratio was 4.67 , and the probability of subsidence was significantly higher in the cage-only group than the cage-with-plate fixation group ( $p=0.049$ ).

At the 24-month follow-up, the fusion rate was 21 out of 24 patients in the one-level cage-only group (87.5\%) and 26 out of 28 patients in the one-level cage-with-plate fixation group (92.9\%). There was no statistically significant difference between groups $(p=0.425)$.

The fusion rate was 10 out of 12 patients in the two-level cage-only group (83.3\%) and 19 out of 20 patients in the twolevel cage-with-plate fixation group (95\%). The fusion rate seemed higher in the cage-with-plate fixation group, but the difference was not statistically significant $(p=0.31$ ).
The measurement of global cervical lordosis showed that the pre-op mean C2-7 angle was $10.90 \pm 10.61^{\circ}$, and the 24-month follow-up mean C2-7 angle was $11.70 \pm 10.31^{\circ}$ in the one-level cage-only group. The pre-op mean C2-7 angle was $10.71 \pm 9.27^{\circ}$ and the 24-month follow-up mean C2-7 angle was $11.16 \pm 9.55^{\circ}$ in the one-level cage-with-plate fixation group. Hence, a kyphotic change was observed compared to the angle at 1-month post-operation, although there was no statistically significant difference between the two groups during the follow-up periods (at pre-op : $p=0.946$; at 24-month follow-up : $p=0.845$ ) (Fig. 3). The pre-op mean C2-7 angle was $6.80 \pm 7.11^{\circ}$, and the 24-month follow-up mean C2-7 angle was $8.53 \pm 7.78^{\circ}$ in the two-level cage-only group. The pre-op mean $\mathrm{C} 2-7$ angle was $7.35 \pm 6.01^{\circ}$, and the 24 -month follow-up mean $\mathrm{C} 2-7$ angle was $10.78 \pm 7.93^{\circ}$ in the two-level cage-with-plate fixation group. Although a change was observed compared to the angle at 1 month post-operation, there was no statistically significant difference (at pre-op : $p=0.825$; at 24-month follow-up : $p=0.441$ ) (Fig. 3).

The measurement of the fusion segment Cobb's angle showed that the pre-op mean angle was $0.13 \pm 2.24^{\circ}$ and the 24 -month follow-up mean angle was $1.04 \pm 2.37^{\circ}$ in the onelevel cage-only group, whereas the pre-op mean angle was 0.62 $\pm 2.70^{\circ}$ and the 24-month follow-up mean angle was $1.78 \pm$ $2.48^{\circ}$ in the one-level cage-with-plate fixation group. Although a change was observed, there was no statistically significant difference (at pre-op : $p=0.476$; at 24 -month followup : $p=0.279$ ) (Fig. 3).

The pre-op mean angle was $-1.62 \pm 1.79^{\circ}$ and the 24 -month follow-up mean angle was $1.37 \pm 2.56^{\circ}$ in the two-level cageonly group, indicative of a change. The pre-op mean angle was $-0.63 \pm 3.02^{\circ}$ and the 24 -month follow-up mean angle was 3.38 $\pm 1.94^{\circ}$ in the two-level cage-with-plate fixation, indicative of a kyphotic change (at pre-op : $p=0.255$ ). In the comparison of the fusion segmental angle at 12-months and 24-months follow-ups, the cage-only group showed a significantly different kyphotic angle (at 12-month follow-up : $p=0.002$; at 24-month

Table 2. Summary of radiologic findings of subsidence, fusion rate between $\mathrm{CO}$ vs. CP

\begin{tabular}{lcccccccc}
\hline Variable & 1 level CO & 1 level CP & OR & $\boldsymbol{p}$-value* & 2 level CO & 2 level CP & OR & \multicolumn{1}{c}{-value* } \\
\hline Subsidence & $11(45.8)$ & $9(32.1)$ & 1.78 & 0.312 & $8(66.6)$ & $6(30)$ & 4.67 & 0.049 \\
Fusion & $21(87.5)$ & $26(92.9)$ & 1.86 & 0.425 & $10(83.3)$ & $19(95)$ & 3.8 & 0.31 \\
\hline
\end{tabular}

Values are presented as number (\%). *Fisher's exact test. CO : cage-only, CP : cage-with-plate, OR : odds ratio 
C2-7 angel

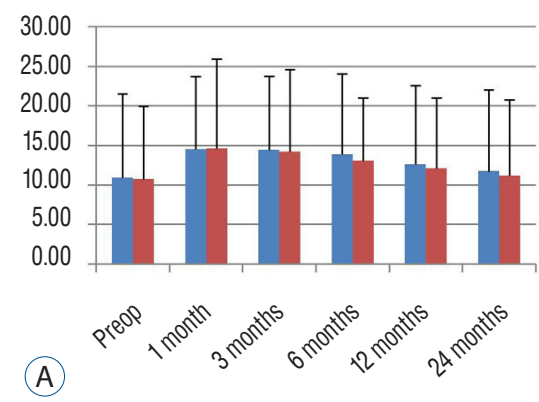

Segmental angle

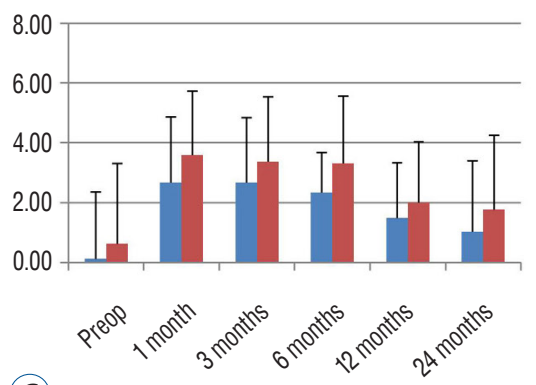

(C)

Adjacent disc height (lower)

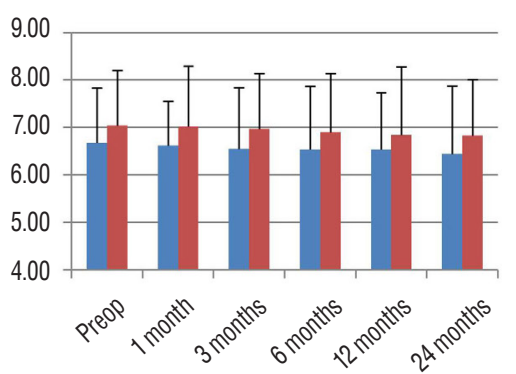

(E)

Adjacent disc height (upper)

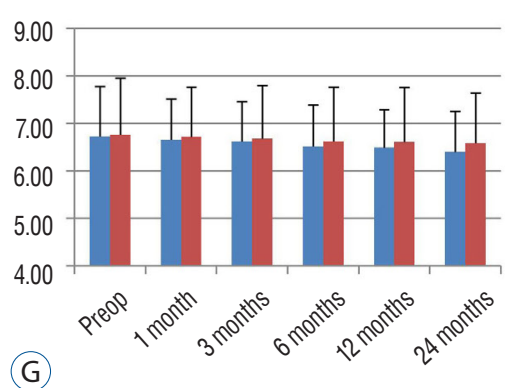

C2-7 angel

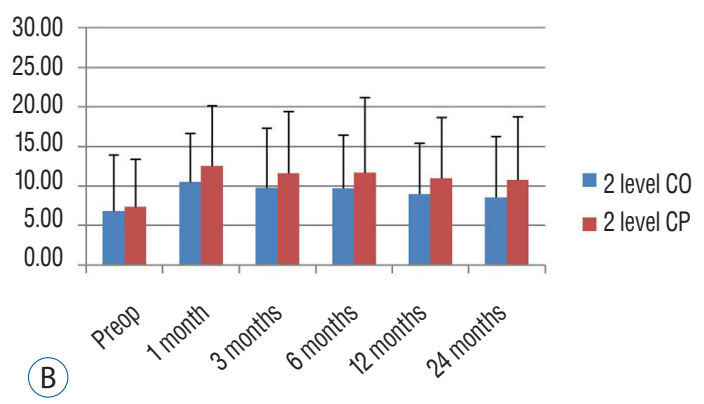

Segmental angle

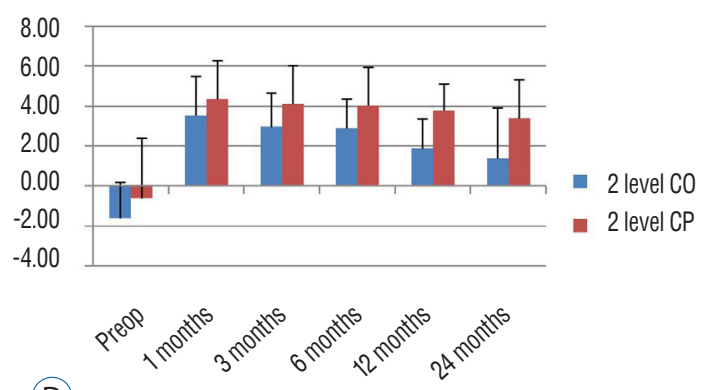

(D)

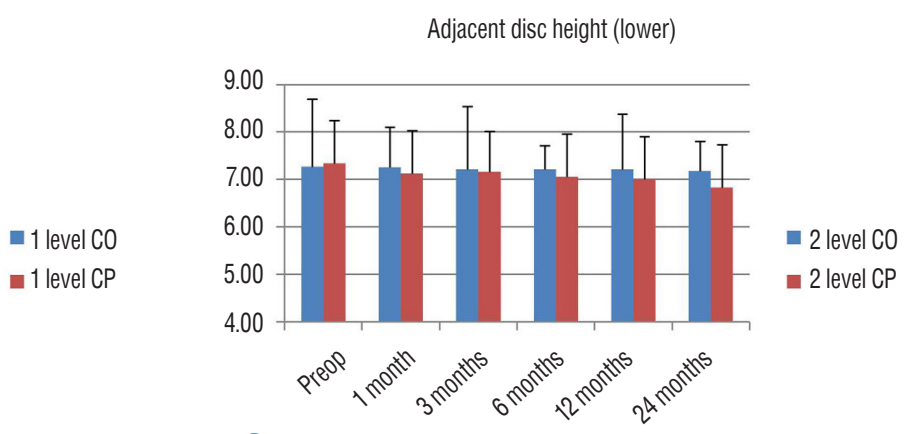

(F)

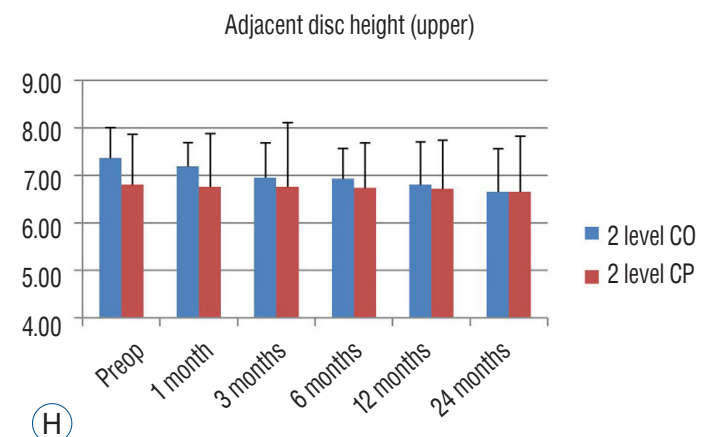

Fig. 3. $A$ and $B$ : Comparison of $C 2-7$ angle $\left(^{\circ}\right)$ between one-level cage-only $(C O)$ vs. cage-with-plate $(C P)(A)$ and two-level $C O$ vs. $C P$ fixation (B). $C$ and $\mathrm{D}$ : Comparison of the fusion segmental angle $\left(^{\circ}\right)$ between one-level CO vs. $\mathrm{CP}(\mathrm{C})$ and two-level $\mathrm{CO}$ vs. CP fixation (D). E and $\mathrm{F}:$ Comparison of the adjacent disc height (lower, mm) between one-level CO vs. CP (E) and two-level CO vs. CP fixation (F). G and H: Comparison of the adjacent disc height (upper, $\mathrm{mm}$ ) between one-level CO vs. CP (G) and two-level CO vs. CP fixation (H). 
follow-up : $p=0.03$ ) (Fig. 3).

In the comparison of the lower adjacent disc height, the preop mean disc height was $6.68 \pm 1.15 \mathrm{~mm}$ and the 24 -month follow-up mean height was $6.45 \pm 1.43 \mathrm{~mm}$ in the one-level cageonly group. The pre-op mean disc height was $7.04 \pm 1.17 \mathrm{~mm}$ and the 24-month follow-up mean height was $6.83 \pm 1.17 \mathrm{~mm}$ in the one-level cage-with-plate fixation group; the change, however, was not statistically significant (at pre-op : $p=0.273$; at 24-month follow-up : $p=0.304$ ).

The pre-op mean disc height was $7.27 \pm 1.42 \mathrm{~mm}$ and the 24-month follow-up mean height was $7.18 \pm 0.63 \mathrm{~mm}$ in the two-level cage-only group. The pre-op mean disc height was $7.34 \pm 0.91 \mathrm{~mm}$ and the 24-month follow-up mean height was $6.84 \pm 0.90 \mathrm{~mm}$ in the two-level cage-with-plate fixation group; as noted above, there was an evident change, but it was not statistically significant (at pre-op : $p=0.877$; at 24-month follow-up : $p=0.213$ ) (Fig. 3).

In the comparison of the upper adjacent disc height, the pre-op mean disc height was $6.73 \pm 1.06 \mathrm{~mm}$ and the 24 -month follow-up mean height was $6.41 \pm 0.85 \mathrm{~mm}$ in the one-level cage-only group. The pre-op mean disc height was $6.76 \pm 1.20$ $\mathrm{mm}$ and the 24-month follow-up mean height was $6.58 \pm 1.06$ $\mathrm{mm}$ in the one-level cage-with-plate fixation group; the change was demonstrable, yet not statistically significant (at pre-op : $p=0.924$; at 24-month follow-up : $p=0.509$ ).

The pre-op mean disc height was $7.37 \pm 0.65 \mathrm{~mm}$ and the 24-month follow-up mean height was $6.65 \pm 0.9 \mathrm{~mm}$ in the two-level cage-only group. The pre-op mean disc height was $6.81 \pm 1.07 \mathrm{~mm}$ and the 24-month follow-up mean height was $6.66 \pm 1.17 \mathrm{~mm}$ in the two-level cage-with-plate fixation group. As before, the change that was found was not statistically significant (at pre-op : $p=0.08$; at 24-month follow-up : $p=0.99$ ) (Fig. 3).

\section{DISCUSSION}

Although there are numerous surgical techniques for ACDF, donor-site morbidity is a complication in autografts using the iliac bone. Thus, interbody fusion using cage fixation is widely used and number of studies comparing the cage-only and cage-with-plate fixation in a fusion using cage fixation have been reported (Table 3).

Numerous results comparing the clinical outcomes between cage-only and cage-with-plate fixation group reported no statistically significant differences. In studies by Lee et al. ${ }^{15)}$ and Song et al. ${ }^{28)}$, however the VAS scores in the cage-with-plate fixation group were significantly better than those in the cageonly group in the one-level ACDF. This can be explained by an imbalance of the cervical lordotic curve resulting from cage subsidence $\mathrm{e}^{20,22}$, or increased tension of the posterior cervical area due to pseudoarthrosis. Regarding the relationship between subsidence and clinical outcome, some studies report no correlation, but a study by Lee et al. ${ }^{16)}$ reported that groups with high subsidence rates had poor clinical outcomes.

In other previous studies, when the fusion rate, subsidence rate and fusion segment kyphosis were compared, the cageonly group had a low fusion rate and high subsidence and kyphosis rates. The success rate has also been reported to decline as the number of levels increases ${ }^{5,23,28)}$. This suggests that the force fixing the vertebral body is lower in the cage-only group than the cage-with-plate fixation group ${ }^{13,24)}$.

There are numerous studies on adjacent segmental degeneration (ASD) and adjacent segmental disease accompanying new radiculopathy or myelopathy after ACDF. The data regarding whether ASD is the natural progression of degenerative spinal disease in the adjacent segment and thus not associated with ACDF, or whether it occurs after the operation due to biomechanical change, are controversial and lack clarity ${ }^{25)}$. The reported risk factors include the presence of ASD prior to surgery ${ }^{27)}$, increased range of motion in the adjacent level and excessive disc space distraction ${ }^{17)}$. These risk factors, however, do not resolve the debate over the origin of ASD. It is notable that the multi-level ACDF has a lower probability of ASD than one-level $\mathrm{ACDF}^{9}$.

The ASD risk was reported to be higher in the cage-withplate fixation group, and sometimes statistically significantly different. Ji et al. ${ }^{11)}$ hypothesized that the high ASD risk in the cage-with-plate fixation group was possibly due to increased fixation force which then increased the level of stress generated in the adjacent intervertebral disks during cervical vertebra motion after surgery.

Recent studies comparing the incidence of ASD in the cageonly group and the cage-with-plate fixation group have used computed tomography and magnetic resonance imaging, as well as plane radiography. Unlike previous reports, in our study, there was no statistically significant difference, but the decrease of adjacent disc height in plane radiography was larg- 
Table 3. Review of previous studies comparing cage-only and cage-with-plate fixation

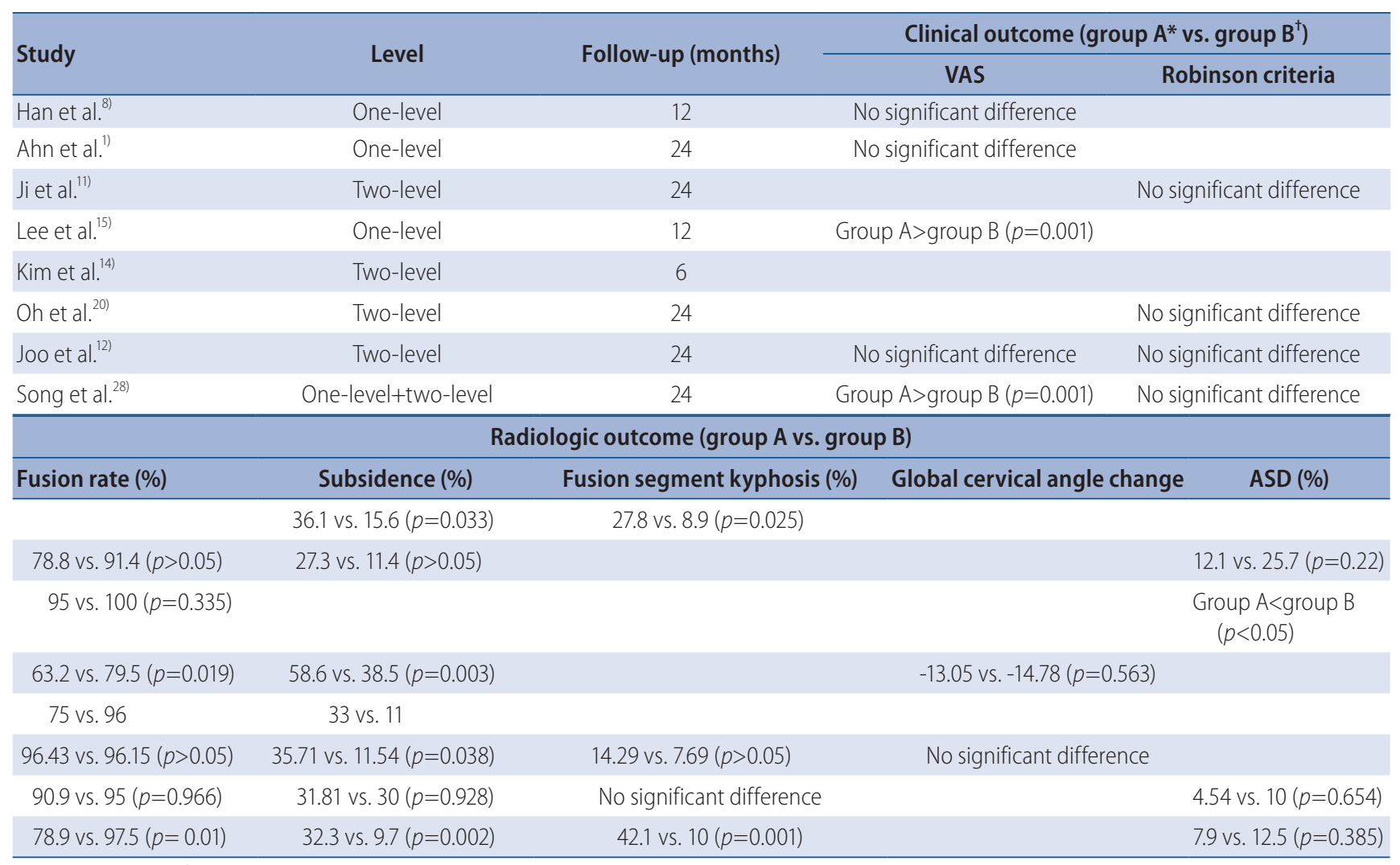

${ }^{*}$ Cage only group. ${ }^{\dagger}$ Cage with plate fixation group. VAS : visual analog scale, ASD : adjacent segmental degeneration

er in the cage-only group, especially in the two levels.

In fact, when relating ASD to clinical outcomes, some data suggest there is no effect on outcomes by $\mathrm{ASD}^{17)}$, whereas other data showed a statistically significant correlation between radiologic ASD and clinical outcomes ${ }^{18}$.

Our study results showed that the fusion rate, subsidence rate and fusion segment kyphosis were not significantly different between the cage-only group and the cage-with-plate fixation group in one-level fusion. We also found in an NDI score comparison that the cage-only group had a better outcome than the cage-with-plate fixation group. This result might be due to complications associated with plate hardware and ASD.

Cage-only has no complications related to plate hardware such as screw loosening, pull-out, and foreign body sensation or dysphagia ${ }^{23)}$. Although ASD was not compared in this study, one report that showed a correlation between ASD and clinical outcomes ${ }^{18)}$ indicated that cage-only operation is likely to be advantageous over cage-with-plate fixation operation in one-level fusion.

Although there was no difference in the fusion rate in twolevel fusion, the cage-only group had a high subsidence rate and showed a kyphotic change in the fusion segment.

It may be insufficient to reflect cervical alignment, because there is no comparison value of parameters such as C2-7 SVA, T1 slope, T1 inlet angle; however, the C2-7 Cobb's angle did not show a significant difference between the two groups, likely because all cervical spinal joints are involved in lordosis ${ }^{15)}$ and other joints can thus compensate for kyphosis.

Although there was no clinical difference observed in this study, the clinical outcomes were poor when the subsidence rate was high ${ }^{16)}$. Furthermore, considering that the success rate decreases in the cage-only operation as the fusion level increases, the cage-with-plate fixation operation is likely to be advantageous compared to cage-only operation in two-level fusion.

This study was limited by the small number of patients in the two-level fusion group and by not having a control group. Thus, a comparative study with a large number of patients is 
needed in the future.

\section{CONCLUSION}

There were reports that adding a cervical plate after ACDF provides a lower subsidence rate and higher fusion rate than cage-only; however, our clinical results showed that the cageonly group had a better NDI outcome than the cage-withplate fixation group in one-level ACDF, with a similar fusion rate and subsidence rate, although more clinical data is required. The fusion rate and clinical outcomes did not show a difference in two-level ACDF; however, the cage-with- plate fixation group had a lower incidence of cage subsidence than did the cage-only group. We conclude that physicians should be aware of this possible disadvantage associated with using cervical plates in one-level ACDF. However, in two-level ACDF, subsidence is more likely to occur in the cage-only group than in the cage-with-plate fixation group, so the adding of a plate should be considered.

\section{- Acknowledgements}

This work was supported by Inha University Hospital Research Grant.

\section{References}

1. Ahn SS, Paik HK, Chin DK, Kim SH, Kim DW, Ku MG : The fate of adjacent segments after anterior cervical discectomy and fusion: the influence of an anterior plate system. World Neurosurg 89 : 42-50, 2016

2. Cho DY, Lee WY, Sheu PC : Treatment of multilevel cervical fusion with cages. Surg Neurol 62 : 378-385; discussion 385-6, 2004

3. Choi MK, Kim SB, Park CK, Kim SM : Comparison of the clinical and radiologic outcomes obtained with single- versus two-level anterior cervical decompression and fusion using stand-alone PEEK cages filled with allograft. Acta Neurochir (Wien) 158 : 481-487, 2016

4. Demircan MN, Kutlay AM, Colak A, Kaya S, Tekin T, Kibici K, et al. : Multilevel cervical fusion without plates, screws or autogenous iliac crest bone graft. J Clin Neurosci 14 : 723-728, 2007

5. El-Tantawy $A$ : Is it possible to eliminate the plate-related problems and still achieve satisfactory outcome after multilevel anterior cervical discectomy? Eur J Orthop Surg Traumatol 25(Suppl 1) : 135-145, 2015

6. Fountas KN, Kapsalaki EZ, Nikolakakos LG, Smisson HF, Johnston KW, Grigorian AA, et al. : Anterior cervical discectomy and fusion associated complications. Spine (Phila Pa 1976) 32 : 2310-2317, 2007

7. Fraser JF, Härtl $R$ : Anterior approaches to fusion of the cervical spine: a metaanalysis of fusion rates. J Neurosurg Spine 6 : 298-303, 2007

8. Han SY, Kim HW, Lee CY, Kim HR, Park DH : Stand-alone cages for anterior cervical fusion: are there no problems? Korean J Spine 13 : 13-19, 2016

9. Hilibrand AS, Robbins $M$ : Adjacent segment degeneration and adjacent segment disease: the consequences of spinal fusion? Spine J 4(6 Suppl) : 190S-194S, 2004

10. Jacobs W, Willems PC, Kruyt M, van Limbeek J, Anderson PG, Pavlov $P$, et al. : Systematic review of anterior interbody fusion techniques for single- and double-level cervical degenerative disc disease. Spine (Phila Pa 1976) 36 : E950-E960, 2011

11. Ji GY, Oh CH, Shin DA, Ha Y, Kim KN, Yoon DH, et al. : Stand-alone cervical cages versus anterior cervical plates in 2-level cervical anterior interbody fusion patients: analysis of adjacent segment degeneration. J Spinal Disord Tech 28 : E433-E438, 2015

12. Joo YH, Lee JW, Kwon KY, Rhee JJ, Lee HK : Comparison of fusion with cage alone and plate instrumentation in two-level cervical degenerative disease. J Korean Neurosurg Soc 48 : 342-346, 2010

13. Kast $E$, Derakhshani $S$, Bothmann $M$, Oberle J : Subsidence after anterior cervical inter-body fusion. A randomized prospective clinical trial. Neurosurg Rev 32 : 207-214; discussion 214, 2009

14. Kim MK, Kim SM, Jeon KM, Kim TS : Radiographic comparison of four anterior fusion methods in two level cervical disc diseases: autograft plate fixation versus cage plate fixation versus stand-alone cage fusion versus corpectomy and plate fixation. J Korean Neurosurg Soc 51 : $135-40,2012$

15. Lee CH, Hyun SJ, Kim MJ, Yeom JS, Kim WH, Kim KJ, et al. : Comparative analysis of 3 different construct systems for single-level anterior cervical discectomy and fusion: stand-alone cage, iliac graft plus plate augmentation, and cage plus plating. J Spinal Disord Tech 26 : 112 118,2013

16. Lee YS, Kim YB, Park SW : Risk factors for postoperative subsidence of single-level anterior cervical discectomy and fusion: the significance of the preoperative cervical alignment. Spine (Phila Pa 1976) 39 : 1280 1287, 2014

17. Li J, Li Y, Kong F, Zhang D, Zhang Y, Shen Y : Adjacent segment degeneration after single -level anterior cervical decompression and fusion: disc space distraction and its impact on clinical outcomes. J Clin Neurosci 22 : 566-569, 2015

18. Litrico S, Lonjon N, Riouallon G, Cogniet A, Launay O, Beaurain J, et al. Adjacent segment disease after anterior cervical interbody fusion: a multicenter retrospective study of 288 patients with long-term follow-up. Orthop Traumatol Surg Res 100 (6 Suppl) : S305-S309, 2014

19. Nambiar M, Phan K, Cunningham JE, Yang Y, Turner PL, Mobbs R : Locking stand-alone cages versus anterior plate constructs in single-level fusion for degenerative cervical disease: a systematic review and metaanalysis. Eur Spine J 26 : 2258-2266, 2017

20. Oh JK, Kim TY, Lee HS, You NK, Choi GH, Yi S, et al. : Stand-alone cervical cages versus anterior cervical plate in 2-level cervical anterior inter- 
body fusion patients: clinical outcomes and radiologic changes. J Spinal Disord Tech 26 : 415-420, 2013

21. Oh K, Lee CK, You NK, Kim SH, Cho KH : Radiologic changes of anterior cervical discectomy and fusion using allograft and plate augmentation: comparison of using fixed and variable type screw. Korean J Spine 10 : 160-164, 2013

22. Park SB, Chung CK, Lee SH, Yang HJ, Son YJ, Chung YS : The impact of menopause on bone fusion after the single-level anterior cervical discectomy and fusion. J Korean Neurosurg Soc 54 : 496-500, 2013

23. Pereira EA, Chari A, Hempenstall J, Leach JC, Chandran H, Cadoux-Hudson TA : Anterior cervical discectomy plus intervertebral polyetheretherketone cage fusion over three and four levels without plating is safe and effective long-term. J Clin Neurosci 20 : 1250-1255, 2013

24. Resnick DK, Trost GR : Use of ventral plates for cervical arthrodesis. Neurosurgery 60(1 Suppl 1) : S112-S117, 2007

25. Shiban E, Gapon K, Wostrack M, Meyer B, Lehmberg J : Clinical and radiologic outcome after anterior cervical discectomy and fusion with stand-alone empty polyetheretherketone (PEEK) cages. Acta Neurochir (Wien) $158:$ 349-355, 2016

26. Singh $P$, Kumar $A$, Shekhawat $V$ : Comparative analysis of interbody cages versus tricortical graft with anterior plate fixation for anterior cervical discectomy and fusion in degenerative cervical disc disease. J Clin Diagn Res 10 : RC05-RC08, 2016

27. Song KJ, Choi BW, Kim JK : Adjacent segment pathology following anterior decompression and fusion using cage and plate for the treatment of degenerative cervical spinal diseases. Asian Spine J 8 : 720-728, 2014

28. Song KJ, Taghavi CE, Lee KB, Song JK, Eun JP : The efficacy of plate construct augmentation versus cage alone in anterior cervical fusion. Spine (Phila Pa 1976) 34 : 2886-2892, 2009

29. Wang JC, McDonough PW, Endow KK, Delamarter RB : Increased fusion rates with cervical plating for two-level anterior cervical discectomy and fusion. Spine (Phila Pa 1976) 25 : 41-45, 2000 